\title{
ACERCA DEL SUICIDIO HÉTERO-REFERIDO Y LA HUELGA DE HAMBRE REIVINDICATIVA
}

\author{
Ángela R. Boitano Gruettner \\ Facultad de Ciencias Sociales e Historia, Escuela de Sociología, \\ Universidad Diego Portales, Santiago de Chile. \\ angela.boitano@udp.cl; aboitanog@gmail.com
}

\begin{abstract}
RESUMEN / ABSTRACT
El artículo analiza el acto de darse muerte por razones políticas (suicidio hétero-referido) y la huelga de hambre como un proceso en que se está dispuesto a perder la vida por razones altruistas. Se sostiene que ambos actos amplían y radicalizan los términos que dan sentido a la vida política y se los concebirá como actos que subvierten el estado de cosas en el ámbito de la polis. El texto sitúa la reflexión en Chile y en el presente histórico, se revisan algunos casos emblemáticos de huelgas de hambre y el conflicto principal entre autonomía y derecho a la vida; se releva el lugar que ocupa el cuerpo como el soporte de esta forma de protesta. Finalmente se proponen algunas conclusiones que permiten interpretar la tensión que provocan estos actos en el orden social.

Palabras Clave: Suicidio hétero-referido, huelga de hambre reivindicativa, vida con sentido, autonomía.

\section{ABOUT THE HETERO-REFERRED SUICIDE AND THE POLITIC HUNGER STRIKE}

The article analyzes the act of giving death for political reasons (heteric-referred suicide) and the hunger strike as a process in which one is willing to lose his life for altruistic reasons. It is argued that both acts broaden and radicalize the terms that give meaning to political life and will be conceived as acts that subvert the state of affairs in the sphere of the polis. The text situates the reflection in Chile and in the historical present, some emblematic cases of hunger strikes are reviewed and the main conflict between autonomy and right to life; the place occupied by the body is relieved as the support of this form of protest. Finally, some conclusions are proposed that allow us to interpret the tension caused by these acts in the social order.
\end{abstract}

KEYWORDS: Suicide hetero-referenced, protest hunger strike, life with meaning, autonomy. 
Me dicen que, adelantándote a los verdugos, has levantado la mano contra ti mismo. Ocho años desterrado, observando el ascenso del enemigo, empujado finalmente a una frontera incruzable. Imperios se derrumban. Los jefes de pandilla se pasean como hombres de estado. Los pueblos se han vuelto invisibles bajo sus armamentos.

Así el futuro está en tinieblas, y débiles las fuerzas del bien. Tú veías todo esto cuando destruiste el cuerpo destinado a la tortura.

B. Brecht (1940)

\section{Introducción}

RA Suicidio, el acto de quitarse deliberadamente la vida, ha sido un tema hegemonizado en su tratamiento por la psiquiatría, la psicología y ciertos enfoques religiosoespirituales. Tratamientos que dan cuenta del modo en que se lo concibe, como una patología, una desviación o como un acto pecaminoso. En este texto se trata acerca de un tipo de suicidio específico que descansa en el acto de darse muerte a sí mismo, cuya diferencia respecto del suicidio autorreferido se puede encontrar no en las intenciones sino la inscripción que opera este acto en la red simbólica. En este último sentido, el suicidio político o la huelga de hambre reivindicativa son actos que amplían y radicalizan los términos que dan sentido a la vida política y se los concebirá a ambos como actos hétero-referidos ${ }^{1}$ que producen una subversión del estado de cosas en el ámbito de la polis. Ambos gestos serán interrogados a fin de esclarecer cuales son los problemas que le plantean al poder.

El suicidio político y la huelga de hambre reivindicativa ponen en tensión ciertos principios como el derecho a la vida y la autonomía, las nociones de ciudadanía abstracta versus situada, entre otras cuestiones. Y sostendremos acá -contra la tesis de que esta forma de protesta inaugura una forma de resistencia pacífica- que es un acto de doble cara: es una autoagresión y una violencia al statu quo pues permite que aparezcan otras coordenadas que definen la situación. En tanto implican renunciar a lo valioso mediante un acto radical, ese mismo propósito desanuda los lazos de dominación y acrecienta la libertad de acción.

Se sostiene que es una renuncia a lo valioso (la vida) y que se inscribiría bajo la fórmula tanto del: "preferiría no hacerlo", como a la de: "me adelanto a tu deseo que no

A diferencia de suicidio autorreferido en que las razones por las cuales se quita la vida a sí mismo radican en un estado de desesperación o desesperanza (Ethos 2011). 
eres capaz de exteriorizar". Se sostendrá en estas páginas que el suicidio político puede ser considerado "el" acto ético por excelencia, siguiendo de cerca la tesis lacaniana del acto de Antígona. Dirá Zizek: “Antígona arriesga toda su existencia social al desafiar el poder socio-simbólico de la ciudad encarnada en el gobernante (Creonte), con lo cual "cae en algún tipo de muerte" (es decir, soporta una muerte simbólica, su exclusión del espacio socio-simbólico)" (2007, p. 281). Sentencia coherente con la idea lacaniana de que "un acto auténtico se produce cuando el sujeto se arriesga a un gesto que ya no es cubierto por el Otro" (Zizek 2007, p. 281). En este gesto, el sujeto subvierte el terreno en que se produce la controversia y se repone la discusión acerca de la legitimidad de los bienes a los que se tiene acceso. Se convierte así en una forma de demanda que radicaliza la reflexión en torno, ya no al acceso igualitario a los bienes sociales existentes, sino al cuestionamiento acerca de si estos son o no "los bienes correctos" (Fraser 2006, p. 49).

El texto se estructura de la siguiente manera: I) analizaré dos citas que reenfocan esta temática en la situación de Chile y en nuestro presente histórico y que tematizan los elementos principales de estos actos de resistencia; II) revisaré algunos casos emblemáticos de huelgas de hambre y el conflicto principal entre autonomía y derecho a la vida; III) insistiré en la relevancia que tiene el lugar que ocupa el cuerpo como el soporte de esta forma de protesta; IV) propondré algunas conclusiones que permiten interpretar los remezones que provocan al orden social estas "salidas de madre" o excesos que escandalizan un orden cuyo foco es el cuerpo.

\section{Suicidio hétero-referido y no-personal}

Quiero comenzar esta ponencia acudiendo a dos citas. Una corresponde a las palabras de Salvador Allende, quien transmite su último mensaje a los/as chilenos/as por radio Corporación en las primeras horas de la mañana del 11 de septiembre de 1973. Y quiero destacar que lo hace en tercera persona, dice: "Habla el Presidente de la República desde el Palacio de La Moneda", pues quien habla no es él sino la primera autoridad de la Nación. No se suicida la persona Salvador Allende, sino que se da muerte un Presidente que desobedece las órdenes de los generales golpistas, reponiendo con este gesto su voluntad de "obedecer el mandato que le entregara el pueblo". Es algo que ya había señalado en un discurso de enero del año 1972 al rememorar a Pedro Aguirre Cerda. Allende recordaba las palabras de Aguirre Cerda quien habría dicho: "Saldré de aquí con los pies hacia adelante, pero jamás abandonaré este cargo que el pueblo me entregó" (Rocha, en Montealegre 2014). Jorge Montealegre cita las palabras de Allende quien en una reunión de gabinete celebrada un día antes del Golpe, dice: "No crean señores que si intentan sacarme de este sillón por la fuerza, yo seré como otros gobernantes de América Latina que se suben a un avión y se marchan al extranjero. ¡No! yo estaré acá y me defenderé hasta la última bala... perdón.... Hasta la penúltima... yo sé lo que haré con la última" (2014, p. 49). Coincido plenamente con Montealegre cuando dice que: "el tema de su propia muerte, casi como un destino escrito, lo propuso reiteradamente en la medida en que habitar y morir en La Moneda devenía un símbolo, 
más que de poder, de haber alcanzado un enclave efímero de la utopía revolucionaria" (2014, p. 50).

La segunda cita que quiero destacar proviene de un audio en que se escuchan las palabras de un huelguistas de hambre ${ }^{2}$ que lleva a cabo esta acción de protesta en agosto del año 1984 tras la expulsión de la Pontificia Universidad Católica de un grupo de estudiantes de diferentes carreras de esa universidad ${ }^{3}$. En el audio se oye: "aquí nosotros hemos dado una victoria enorme (sic), hemos dado una lucha grande.... y no nosotros, los pelaos que estamos aquí, sino todo el conjunto del pueblo que ha ido asumiendo conciencia acá ( $\mathrm{sic}$ ), ha dado pasos que no habían dado nunca antes (sic) y eso demuestra que esto no es solo un conflicto universitario sino un conflicto que ha asumido el pueblo" (Palacios 2014). No hablan de sí mismos, hablan por otro, encarnan a un actor colectivo que debe ser representado.

Ambos casos, el suicidio de Allende y la huelga de hambre reivindicativa, son una especie de lección moral (textualmente dicho en el último discurso de S. Allende) que se supedita -por cierto-a una posición política. Ya lo mencionaba en la introducción a este texto, ambos son actos radicales que efectúan una ruptura de la cotidianeidad que obliga a pensar pues quiebran la rutina. En la huelga de hambre hay un "último intento" de mensaje que se caracteriza por estar inscrito en el cuerpo y que espera ser descifrado. En el suicidio político ocurren derivas distintas a las que produce la huelga de hambre, pues esta última es un proceso que permite "pensar" a los interlocutores del drama. El suicidio en cambio cierra, temporalmente al menos, la significación, aunque tarde o temprano es re-significado, cuestión que muestra muy bien Montealegre en su descripción del tránsito de Allende de caricatura a monumento.

Nos enfocaremos indistintamente tanto en la huelga de hambre como en el suicidio reivindicativo, aunque la primera nos permite articular mejor los elementos que esta demanda supone. Según Butler: "ingresamos a la existencia, por así decirlo, a partir de la demanda, y algo de nuestra existencia prueba ser precario cuando dicha demanda fracasa" (2006, p. 164). Así como señalan numerosos informes que tematizan la huelga de hambre, no podemos olvidar las huelgas de hambre de personas mapuches que años recién pasados en Chile han impactado a la opinión pública al poner en tensión el modo en que son (mal)tratados por el Estado. La huelga de hambre se lleva a cabo luego de un periplo de desconocimiento que nos interpela de una manera radical. ¿Quién la hace? Quien no puede hablar. O quien habla, pero sin estructura que haga audible esa demanda. Ya lo decía Spivak, el/la subalterno/a no puede hablar. No sostiene Spivak

2 De esa huelga de hambre participaron: Manuel Peña, Patricio Ponce, Jorge Zúñiga, Julio Cesar Ibarra, Max Benavides y nuestro excompañero y amigo Edgardo Bousquets, éste último años más tarde decidió probablemente que la vida conseguida seguía sin tener el sentido que a él le parecía exigible.

3 La P. Universidad Católica estaba intervenida por la dictadura militar y recién había dejado la rectoría el vicealmirante Jorge Swett, asumiendo en su lugar el Dr. Juan de Dios Vial Correa. 
que el silenciamiento se dé en el plano de la existencia, sino en el de la representación. El/la subalterno/a habla, pero no hay una estructura que haga traducible la demanda. En efecto, quienes tienen menos posibilidades o gozan de menos representación o autorrepresentación son más vulnerables al maltrato o la deshumanización (cfr. Butler 2006); en ese sentido el suicidio revelaría la humanidad que se ha maltratado.

Darse muerte, no es morir sencillamente. No es querer la muerte porque se considera a la vida sin sentido, por el contrario, el acto de darse muerte repone el sentido como lo esencial a la vida. Lo que se rechaza es esta vida tal cual está organizada, se ama la vida, pero se la quiere de una manera que está inscrita en el acto de morir: se la quiere de una radicalidad imposible de coexistir con la pragmática de esa vida que se tematiza en el acto de morir. Es importante esta distinción que se hace entre vida "a secas" y vida "culturalmente significativa". La huelga de hambre pondría en evidencia que la primera es la que garantiza un Estado que no respeta las diferencias de sus miembros y la aspiración de estos a gozar de un estatus igualitario. Los/as huelguistas expresan, por su parte, que "esa" vida no es a la que aspiran y que es "esa" la que puede ser puesta en riesgo.

Quienes inician o se suman a una huelga de hambre podrían ser descritos como esos seres espectrales de los que trata Butler (2006). Ella señala que son seres que debieran haber sido asesinados, o muertos, pero que ya que no han sido efectivamente muertos quedan penando y constituyen, por eso mismo, una amenaza radical. Tan radical que instalan la pregunta acerca de ¿qué es lo que hace humano a un ser humano? ¿Qué es un ser humano como tal? No olvidemos que, según Arendt, algo se quebró con el hallazgo de los seres humanos en campos de concentración, lugar en el cual lo único que puede decirse de ellos es que son humanos desprovistos de toda otra cualidad sociopolítica base de su ciudadanía. Son un puro cuerpo. Una vida nuda.

Diríamos, en ese sentido, que los mapuches en huelga de hambre ya han sido espectralizados, han sido reducidos pues se ha intentado con ese grupo la muerte cultural -al menos-(cfr. Boitano 2015). Los estudiantes de la P. Universidad Católica que llevan a cabo una huelga de hambre en agosto de 1984 anudan su demanda por reingresar a sus carreras a todas las demandas que se habían cristalizado en las diversas capas sociales de este país en dictadura. El suicidio de Allende fue una muerte anunciada, se adelanta en unas pocas horas a la muerte que le tenían reservada los militares. Se anticipan a la condena, tal como Antígona, la aceptan y la ejecutan por propia mano. Se sobrevive, posteriormente al suicidio, por la autoridad simbólica del Nombre.

Zizek nos permite también enfocarnos en cierta teatralidad elemental de la condición humana (2005, p. 147) que está implicada en morir frente la mirada de otros, o del gran Otro. El suicidio de Allende es público, se hace con publicidad, se lo anuncia por la radio, en tanto la huelga de hambre también debe ser pública, pues es de esa manera que en el futuro podemos ocupar el lugar de los que "miran" la escena. Esta cuestión nos lleva a refutar a quienes sostienen que la muerte no puede ser proyecto, por el contrario, el suicidio del que hablamos acá contiene un proyecto. Con la huelga de hambre queda a la vista "lo humano como tal" presentado como una sublime presencia humana que se degrada a la vista de un público. El que se suicida es el cambio, según 
Zizek y la fórmula de Ghandi "sé tú el cambio que te gustaría ver en el mundo" (2005, p. 199), nos pone a la vista que el que se suicida no espera que cambie objetivamente el mundo, el/ella lo es, lo hace. Supone, por tanto, que el sujeto quiere vivir de alguna manera y ser parte de ese mundo que cambiará, aunque no sea él mismo quien viva en ese mundo mejor, sino otros, de ahí que sea un suicidio heterorreferido. Y este es un tema que se abre con la huelga de hambre y el suicidio reivindicativo. El sujeto quiere vivir de cierta manera y se concibe a sí mismo como parte de un colectivo. En efecto, la muerte cambiará la forma del mundo no para sí sino para los otros y, en este sentido, es un acto radicalmente altruista.

Hay cierto consenso en definir a la huelga de hambre como una herramienta de denuncia y de protesta social pacífica y extrema, hétero-referida, y cuya pretensión es poner en evidencia una situación de injusticia. En ella se tensionan valores centrales que se atribuyen a los individuos en nuestras democracias liberales: el derecho a la vida y el goce de la libertad de decidir. No coincido con lo señalado por Precht y Faundes quienes sostienen que esta se produce "cuando las demandas sociales colisionan con un Estado que ve agotada su capacidad de respuesta" (2013, p. 334); por el contrario, creo que la medida extrema se produce en virtud de que este es un acto político que devela las decisiones que hacen imposible oír las demandas. Por lo mismo, me parece necesario asumir la tesis de Spivak quien señala que no puede hablar el subalterno pues la huelga de hambre muestra el límite de lo que el Estado puede "escuchar".

Decíamos que se tensionan el derecho a la vida y el ejercicio de la libertad, valores caros a nuestras democracias liberales. Pero ¿de qué noción de vida y de libertad hablamos? ¿No será ya tiempo de rechazar plenamente la idea ilusa de neutralidad valórica del liberalismo? Y, contra las pretensiones del universalismo, admitir que la sociedad liberal no es en realidad un espacio de encuentro entre diversas expresiones culturales, sino una expresión política circunscrita a un sector, incompatible frecuentemente con otros, léase musulmanes, mapuches o sencillamente sectores populares que valorizan acuerdos fieles a otros paradigmas (cfr. Taylor 1997). El liberalismo hegemonizaría una serie de significantes centrales para el mundo occidental, tales como autonomía, sí mismo-otro, individualidad, etc., todos bajo el significado de "libertad". El liberalismo naturaliza su propio concepto de libertad y lo difunde como si fuera universal, dejando de ver el espacio preconstruido discursivamente que permite que se defina libertad de "esa" manera, como si fuera la única. Sostengo contra eso que no hay libertad como tal, en sí misma o fuera de un sistema de diferencias. Es en la relación entre elementos desde donde se configura finalmente esta definición y "esta libertad (la del liberalismo)", no es más -ni menos- que la libertad del mercado, en donde los individuos se sitúan idealmente en igualdad de condiciones en vistas a la transacción de bienes de diversa índole" (Boitano 2015, p. 363).

Dicho lo anterior, considero en este texto que el suicidio - a secas y también el suicidio reivindicativo, así como la huelga de hambre- es una medida moralmente lícita y no entraré en el debate que sostienen algunos autores que la consideran reprobable per se en tanto tipo de suicidio intencional que, si bien se diferencia del suicidio individual, no dejan de ver en la huelga de hambre que se ejecuta con intenciones altruistas "una maldad moral... al intentar la propia muerte" (Miranda-Montecinos et al. 2015, p. 77). 
Estos planteamientos asocian huelga de hambre y suicidio, siendo este último el que carga de ilicitud a la primera. Lo que, por otra parte, desconoce la Declaración de Malta (años 1991, 1992, 2006). Es el tenor de los planteamientos de Soto Kloss quien se ampara en una tradición moral integrista. También Ugarte Godoy señala que el homicidio, el suicidio y la mutilación son intrínsecamente malos y nada puede justificarlos, pero nada dice en relación con la muerte de civiles en bombardeo a buques de guerra. Son las contradicciones que surgen cuando no se hacen las distinciones necesarias. Pedro De La Noi, profesor del Instituto de Filosofía de la PUC, al que pertenecía uno de los huelguistas de hambre del caso del párroco de la Parroquia San Roque, llega a afirmar en carta al almirante Merino que "una legislación que tipificara el delito de huelga de hambre, en cuanto escándalo público, cuando atenta contra la salud y la vida o se presenta como tal, tendría consecuencias positivas" (Precht 2013, p. 348). El historiador Sergio Villalobos va más lejos y propone considerarla como un acto terrorista ${ }^{4}$. No nos detendremos en este tema.

\section{Recorrido por algunas huelgas de hambre}

Haremos un breve recorrido por las marcas que han dejado ciertas huelgas de hambre, muchas de ellas protagonizadas por sujetos que estaban prisioneros. En 1920, Irlanda, Terence Mac Swiney muere tras 63 días sin comer (Cervelló 2016, p. 63). Mahatma Ghandi ayunó por 21 días en el año 1943 y éste es, probablemente, el episodio que legitima la huelga de hambre como herramienta de movilización social, siendo un acto que se inscribe en el marco de la "no-violencia-activa" y que le imprime a la huelga de hambre un carácter "sacrificial" (Precht 2013, p. 335). En los años 40 en Irlanda y España se produjeron muertes por esta causa. Pero es en los años 70 que se acrecienta esta forma de resistencia política. Miembros del IRA Michael Gaughan y Frank Staag mueren en 1974 y 1976, respectivamente, tras 60 días de ayuno (Cervelló 2016, p. 65). Aunque tal vez el caso más conocido fue el de Robert Sands el año 1981 quien muere tras 66 días en huelga de hambre a la edad de 27 años (Informe Ethos 2011). Otro caso emblemático ocurre en España, en él un grupo de sacerdotes protagoniza este acto el año 1972 y luego en 1989 se produce un episodio importante que llevan a cabo miembros del GRAPO.

En Chile también hay una larga historia de huelgas de hambre y suicidios por razones reivindicativas. Me detengo arbitrariamente en el año 1984 -aunque hubo huelgas importantes antes, la del año 1978 llevada a cabo por familiares de detenidos desaparecidos-, pero esta que se produce el año 1984 es llevada a cabo por estudiantes

$4 \quad$ Villalobos R., Sergio, 1930-. "La huelga de hambre también era terrorismo" (entrevista) [artículo] Emmanuel Ganora. Las Últimas Noticias (Diario: Santiago, Chile). Archivo de Referencias Críticas. Disponible en Biblioteca Nacional Digital de Chile http://www. bibliotecanacionaldigital.cl/bnd/628/w3-article-333120.html . Accedido en 6/10/2017. 
de la PUC miembros del grupo antidictadura Poder Popular". Se llama a este "el caso del párroco de San Roque", pues se hace pública debido a la acusación que hacen autoridades de la PUC hacia el rol del padre Gerard Wheelan, a quien acusan de asistir a este grupo en el suicidio. Él se defiende calificando a este acto no como suicidio sino como "un acto de caridad...un sacrificio que se han impuesto los huelguistas de hambre como forma de lucha por el derecho de ellos y de otros para estudiar" (en Soto Kloss 1985, p. 148).

Estos últimos años en Chile hemos sido testigos de cómo diversos grupos activistas mapuches han desarrollado prolongadas huelgas de hambre. El año 2003 los Lonko Pascual Pichún y Aniceto Norin, el año 2007 la "Chepa" (Patricia Troncoso), el año 2010 treinta y cuatro presos mapuche ayunaron por 82 días y el 2011 lo hicieron por ochenta y siete días; recientemente (año 2017) se depuso una huelga de hambre que duró 115 días.

Sostendré acá que la huelga de hambre no es un suicidio, pues no está caracterizada por la voluntad de morir, sino que el eje que la define es una finalidad reivindicativa. Es más, diremos que quienes hacen una huelga de hambre quieren "racionalmente su vida o la vida libre de su pueblo, pero asumen un riesgo vital en la búsqueda de un bien que legítimamente han definido como prioritario" (Precht 2013, p. 336).

¿Qué es lo que está en juego en la huelga de hambre o en el suicidio político? Prima facie el derecho a la vida y el derecho a la autonomía. Principios que también animan la discusión en torno al aborto, del derecho a la eutanasia, entre otros temas afines en que la vida parece un bien al que es difícil renunciar. Bien vale aquí atender a lo que señala Tugendhat (2002), quien se cuestiona que fijemos sin más que la muerte es un mal y la vida un bien; para él la vida es neutra: "en sí no tiene sentido, me puede parecer igualmente plena que vacía y esto depende ahora también de mí: yo puedo darle sentido. Y si no lo logro, me parece a menudo (no necesariamente, como se va a mostrar) insoportable" (2002, p. 172). Finalmente le tememos al vacío de la vida, pero no al de la muerte.

¿Pero es solo eso lo que plantea una amenaza tan feroz al orden de las cosas? La vida parece, por cierto, un hecho más saliente que la autonomía individual, de hecho,

5 El Poder Popular fue la tesis que desarrolló el MIR en torno a su acción político-social como lucha de acción directa, y se llevaba a cabo principalmente mediante la toma de terrenos por parte de campesinos y pobladores, y a través de la toma de fábricas por los trabajadores. Esta propuesta planteaba que la construcción política y social revolucionaria debía conjugar la vanguardia revolucionaria y el movimiento popular. Esta base social amplia era imprescindible para que la lucha revolucionaria consolidara la insurrección popular y construyera una sociedad más justa. Los pobres del campo y la ciudad debían ser los protagonistas de su propia historia de liberación y emancipación. En dictadura, algunos grupos de resistencia asumen estas tesis. Entre los diversos movimientos opositores a la dictadura que surgen entre el 1983-1986 está el caso emblemático de un movimiento que aúna a estudiantes de la PUC denominado "Poder Popular", que pone en jaque la conducción del malestar social que esperaban hegemonizar partidos tradicionales que se habían agrupado en el MDP (Movimiento Democrático Popular). 
esta última habría que probarla. Ejemplo de ello es que, por ejemplo, en Holanda cuando se atiende a la petición de eutanasia hay que despejar la calidad de autónoma de la decisión y dejar clarísimo que el individuo no está siendo manipulado y se encuentra en posesión plena de sus facultades mentales. La vida, en cambio, es inobjetable. Aunque esto también podríamos cuestionarlo. Agamben trata ampliamente este tema en Homo sacer (1998), donde señala que hoy ya no está tan claro cuándo adviene la muerte y que, de hecho, ese límite se ha modificado. Ya no aceptamos que la muerte cardíaca sea el fenómeno que marca el término de la vida biológica. Y eso es un muy buen argumento para sostener que -ya que depende de una decisión- la misma definición de muerte es un hecho político. Es más, la vida se situaría, en la perspectiva de la biopolítica moderna, "en una encrucijada entre la decisión soberana sobre esa vida suprimible impunemente y la asunción del cuidado del cuerpo biológico de la nación" (Agamben 1998, p. 180).

¿Por qué no escandalizan otros riesgos que toman las personas, como ser guardaespaldas, en que se pone la vida en riesgo por dinero, o el Servicio Militar? ¿Y la pena de muerte en que derechamente el Estado dispone de la vida de un individuo? (Precht 2013). Esto, dicho con respecto a la vida ¿Y en relación con la libertad?

Habría que poner en el tapete el tema de la libertad/autonomía para fines ilícitos o para fines lícitos. Por otra parte, ¿el derecho de libertad admite el derecho a la propia muerte? La pregunta es si la posibilidad fáctica de producir la propia muerte es o constituye una manifestación del agere licere que debiera consagrar el reconocimiento de la autonomía personal. El caso es que la huelga de hambre reivindicativa no implica la mera voluntad de darse muerte sino la voluntad de luchar por un derecho para el cual se pone en entredicho si la vida vale la pena de ser vivida sin el goce de ese derecho. Plantea, lo decíamos, un conflicto entre la vida y la autonomía. Aunque sospechamos que no es solo eso lo que está en juego. Lo más amenazante es en verdad la radicalidad que se advierte en el acto, pues definitivamente pone de cabeza la noción de bienes a los que se puede tener acceso y de justicia propuesta por la sociedad mayoritaria.

La huelga de hambre tensiona el modo en que nuestras democracias liberales enfrentan la diversidad. Por lo que hay que revisar -al menos- las nociones de vida y de libertad, lo mencionábamos antes. En el contexto del valor que se da al individuo desvinculado y autónomo que suponen las teorías del contrato resulta incomprensible e irracional la actitud de un individuo que deja de ingerir alimentos en protesta por la demanda de un derecho, sobre todo si estos derechos son colectivos. Cito a Domingo (en Precht 2013, p. 340) para señalar que probablemente la huelga de hambre ilustra un escenario en que "desaparece el ciudadano como individuo, átomo social o sujeto abstracto o desenraizado y emerge el ciudadano como persona o presencia comunicada que compartiendo fines y metas hace valioso el mundo porque lo construye en clave de corresponsabilidad". Y ese es tal vez el acto más disruptivo: "mostrar que el orden establecido no es algo necesario o natural, sino profundamente contingente, sujeto a la deliberación" (Boitano 2014, p. 128).

Y en este punto aludiremos brevemente al concepto de contradicción performativa. Es una discrepancia entre lo que decimos y lo que hacemos al decirlo, la cual no es producto de un error o una inconsistencia, sino que es parte de una práctica de resistencia que subvierte un campo en el que se da la controversia. Podemos observar 
una contradicción performativa cuando se declara ser poseedor de un derecho, en el momento en que estos se ejercen en la práctica, pero cuando institucionalmente han sido negados. Un ejemplo de este tipo de contradicción: se ejerce el derecho a la recuperación de territorios usurpados por el Estado en la apropiación de hecho de estos, en la "toma de terrenos". O se ejerce el derecho a la libre expresión, expresándose sin permiso de la autoridad. Ambos casos suponen una contradicción performativa desde el momento en que se ejercen derechos que no se poseen legalmente. Y eso puede ser un elemento central en la huelga de hambre: se ejerce el derecho de dar sentido a la vida renunciando a ésta tal cual está organizada. Se trata, mediante este concepto, de proponer una manera de comprender el reclamo desde una perspectiva que desate el nudo ciego que imposibilita el diálogo. Butler dirá:

Se trata, sin duda, de un tipo de performativo político en que lo ilegal es precisamente la reivindicación de volverse un ilegal -una reivindicación que no obstante se realiza desafiando a la misma ley a la que se le exige reconocimiento-(2009, p. 87).

\section{El cuerpo como texto y mensaje}

Es ineludible la referencia al cuerpo, pues en ese lugar se verifica la huelga de hambre, también el del suicidio político. En este punto podemos comprender al cuerpo como un espacio privilegiado en que la vulnerabilidad humana se verifica en su dimensión más brutal. La huelga de hambre es un tipo de "duelo público" (Butler 2006, p. 74) del que se dispone y que hace visible las normas que "producen" lo humano. Cuando dejo de ingerir alimentos y se arriesga la vida, es este un riesgo político que desafía ciertos mandatos culturales, en particular aquellos vehiculados por la reformulación reciente de los Estados nación.

Agamben nos permite pensar lúcidamente en torno a esta idea. Él señala que, en la organización de los Estados nación occidentales desde el ascenso del nazismo, e incluso antes, se comienza a considerar que ya no es la libertad el eje de la esencia humana sino el encadenamiento del ser humano a su cuerpo (1998, p. 192). El ser humano que lleva a cabo una huelga de hambre ofrece su cuerpo, pues así se escenifica la situación en que ya ha sido despojado de su condición política y reducido a la nuda vida (Agamben 1998, p. 217).

Esta escena del sujeto que deja de comer, del que se suicida en frente de otros, etc., es una representación de un hecho que además ocurre en otro lugar: en el cuerpo social. En efecto, hay vidas que no merecen ser vividas y es esa la idea que quisiera remarcar. Ahora bien, estas vidas que han sido deshumanizadas se hacen "cuerpo" en la huelga de hambre. En el caso particular de la huelga de hambre mapuche, aunque habría que señalarlas en plural, son acciones que ejecutan personas miembros de grupos que consideran que su "estatuto ontológico" de sujetos ya ha sido suspendido. En este acto sostienen que ya les ha sido retirado su derecho a ejercer ciudadanía. Y ciertamente, aunque aquí no es el lugar, habrá que decir que no hay una única noción de ciudadanía, pero de la que se habla acá es de la ciudadanía igualitaria que subyace al principio del universalismo propio del liberalismo. 
Propongo acá pensar la huelga de hambre como un dispositivo que hace que algunas muertes dejen de pasar desapercibidas. La huelga de hambre "espectaculariza" de esa manera el hecho de que a algunas personas ya las mataron en vida o las redujeron a una nuda vida producto de un "discurso deshumanizador" (Butler 2006, p. 61), y a quienes ahora solo les resta esperar su muerte definitiva. Pero el escenario en que se ejecuta esta muerte lenta permite que quede registro de ese maltrato y eso hace posible visibilizarlas. Usualmente, las demandas que sostienen los huelguistas de hambre representan las experiencias de vidas ya negadas, las que, al morir en público, adquieren una cierta dignidad. Me detendré en este punto al finalizar, en la idea de que la huelga de hambre y el suicidio político reponen lo que para Butler es una de las únicas salidas a la deshumanización, la insistencia en que una especie de reconocimiento de vulnerabilidad humana común puede sentar las bases para cierto encuentro; la cito:

Es necesario percibir y reconocer cierta vulnerabilidad para volverse parte de un encuentro ético, y no hay ninguna garantía de que esto ocurra. Siempre está la posibilidad de que no se la reconozca y que se constituya como "irreconocible", pero cuando esta vulnerabilidad es reconocida, este reconocimiento tiene el poder de cambiar el sentido y la estructura de la vulnerabilidad misma. En este sentido, si la vulnerabilidad es una condición para la humanización y la humanización tiene lugar de diferentes formas a través de normas variables de reconocimiento, entonces la vulnerabilidad, si es que va a ser atribuida a cualquier sujeto humano, depende fundamentalmente de normas existentes de reconocimiento (Butler 2006, p. 70).

La huelga de hambre nos comunica algo, nos interpela haciendo visible la precariedad de la vida, al mismo tiempo define una ética de la no-acción o pasividad. Esta última incluye en su seno la agresividad de toda omisión. Porque es posible advertir cierta agresión en el ejercicio de no ingerir alimentos o en el acto de dispararme un balazo frente a otro. Examinémoslo desde Benjamin. Este se refiere el hecho de que todo Estado concede el derecho a cierto ejercicio de la violencia, es el caso del derecho a huelga. Nos referimos a la huelga laboral, esta "representa, desde la perspectiva del sector laboral enfrentada a la violencia del Estado, un derecho de utilización de la violencia al servicio de ciertos fines" (Benjamin 1998: 27), cuestión que está sujeta a una serie de regulaciones pues nada teme más el Estado y el derecho moderno que aquella violencia que amenaza con fundar un nuevo derecho o -peor aún- cuestionar el derecho mismo en su origen.

No debemos olvidar que el origen del Estado-nación moderno es violento. Ahora bien, cuando la violencia que permite el Estado se dirige a resolver temas parciales (laborales por ej.) resulta más aceptable que en aquellas ocasiones en que tiende a subvertir el campo mismo en que se estructura el conflicto (Zizek 2009, p. 132). Es lo que se verifica cuando comparamos este derecho a la huelga laboral con la más radical protesta que toma la forma de una huelga de hambre. En esta práctica de resistencia hay una especie de abstención, una insoportable pseudoactividad que rechaza el mismo marco en que se actúa y, según Zizek, enfrentaría a la vacuidad de las democracias actuales en que "a veces no hacer nada es lo más violento que puede hacerse" (Zizek 2009, pp. 255-6). 
La huelga de hambre, finalmente, tensiona las nociones de vida vivible y muerte lamentable, lo humano y lo inhumano. Y el cuerpo debilitado por la inanición lleva al campo visual un grito de lo humano que subvierte los límites de lo que cada sociedad decide que es mostrable, escuchable o inaudible y ocultable. Rompe ciertos esquemas de inteligibilidad que se consideran tácitos. A propósito, Butler señala:

En la guerra de Vietnam, fueron las imágenes de niños ardiendo y muriendo a causa del napalm las que despertaron en el público estadounidense un sentido de shock, indignación, remordimiento y pena. Eran precisamente imágenes que se supone que no teníamos que ver, y que trastornaron el campo visual y el sentido completo de la identidad pública que construyeron sobre dicho campo (Butler 2006, p. 186).

Una imagen puede fracturar el campo hegemónico de la representación, en este caso, la visión de la precariedad de esas vidas que dejan de vivir lentamente es una metáfora de las vidas que estamos destruyendo lentamente. Ambos tipos de huelga son casos significativos de puesta en cuestión del orden del derecho. Tal como decíamos a propósito de Benjamin, el derecho a huelga que concede el Estado a los trabajadores es una situación en que el Estado mismo pone al límite la relación entre la violencia y el derecho. Habría ahí una concesión a la libertad de las personas. En un caso pueden dejar de producir, en el otro pueden dejar de comer, todo hasta un cierto punto en que pueden ser obligadas a ambas cosas. Hay una violencia en ese lugar que consiste en la puesta en escena de una violencia contra otra, pues se ponen en tensión los conceptos de vida a secas versus vida buena o justa, una aspiración a valorar la vida no como bien biológico, sino cultural. El hecho es que a través de la huelga de hambre se pone en tela de juicio la idea de que el Estado garantiza la vida, pero no -y ésta es la razón de la protesta- el derecho a la vida culturalmente significativa. En efecto, la huelga amenaza con destruir no solo la vida "nuda" sino que amenaza el orden de derecho estatal. Dirá Derrida que el Estado tiene miedo de "la violencia fundadora" (1992, p. 1163; cfr. Benjamin 1998) que este acto implica, pues cuenta con el potencial de transformar las relaciones de derecho y posicionarse como "teniendo un derecho al derecho" (Derrida 1992, p. 163) refundándolo. Y el derecho que se fundará es el que legitima retrospectivamente la violencia ejercida.

\section{Reflexiones finales}

Para terminar, quiero dejar planteada la noción de "performatividad del reclamo" -o forma en que éste es realizado [performed]- pues nos permite hacer algunas preguntas. "Hacer un reclamo en nombre propio supone que uno habla el lenguaje en el que el reclamo puede ser hecho, y lo habla de tal manera que el reclamo puede ser oído" (Butler 2011, p. 182). ¿En qué lenguaje se formula el reclamo de los huelguistas de hambre? ¿Cómo hacer audible aquello que no es posible de ser dicho en el lenguaje del dominado? La huelga de hambre como forma de reclamo lleva a desconfiar de las pretensiones de universalidad del lenguaje del poder y propone versiones alternativas 
de universalidad. Por otra parte, al formular este reclamo se produce un sujeto al que no se le ha dado la prerrogativa de ser sujeto, sino una imagen espectral de lo humano (Butler 2011, p. 183).

Diremos que esa forma de reclamo repone una demanda particular, sí. A la vez, esas resistencias se anudan a otras diferencias y, en ese gesto, se propone una noción de universalidad en la que estarían incluidos aquellos que se encuentran siempre fuera de sus términos. Repone lo particular e instala un desorden, pues lo universal es el orden. La particularidad produce una ruptura que es imperdonable, pues señala la huella de una legalidad alternativa que aparece en la consciente esfera pública como su futuro escandaloso (Butler 2001, p. 62).

La reivindicación misma que encarna la huelga de hambre se ubicaría en una lógica que no parece ser la búsqueda del reconocimiento, sino precisamente anular esa dependencia del Otro. Así se puede entender la muerte-suicidio como una huida de la significación y como gesto que permite inaugurar un orden alternativo. Esto nos permite anudar las consecuencias de la aceptación teórica de la negatividad constitutiva de todo sujeto (individual o colectivo) y del orden social con las lógicas y trayectorias que adoptan los movimientos sociales que intentan radicalizar la democracia.

El suicidio político y la huelga de hambre aparecen como una "salida de la significación", el único acto ético por excelencia y que detiene el deslizamiento de los significantes (cfr. Laclau 2009). Quien hace una huelga de hambre está dispuesto a morir y no desea seguir discutiendo acerca del significado de sus actos, con la muerte se le da la puntada final. Quedan los vivos que luego se apropiarán de los significantes, pero él o la que muere ha tocado lo real mediante lo simbólico. Es decir, se renuncia a "resolver una variedad de problemas parciales" (Zizek 2009, p. 132) y se introduce otro horizonte de lo que puede ser posible.

\section{Referencias bibliográficas}

Agamben, G. (1998), Homo sacer. El poder soberano y la nuda vida. Valencia: Pretextos.

Aristóteles (1993), Física. Libros I y II. Trad. Marcelo D. Boeri. Buenos Aires: Editorial Biblos.

Benjamin, W. (1998), Para una crítica de la violencia y otros ensayos. Madrid: Taurus.

Boitano, A. (2015), "La exclusión del otro desde la elite y el Estado". POLIS Revista Latinoamericana. Vol., No 41, 2015.

(2014), Grupos minorizados: identidades politicas, tipos de ciudadanía y formas de reconocimiento. Un análisis filosófico de la demanda mapuche en Chile (Tesis doctoral inédita). P. Universidad Católica de Chile. Santiago de Chile.

Butler, J. (2006), Vida precaria. El poder del duelo y la violencia. Buenos Aires: Paidós.

(2004), Lenguaje, poder e identidad. Madrid: Síntesis. 
Butler, J. y Spivak, G. (2009) ¿Quién le canta al estado-nación? Buenos Aires: Paidós.

Butler, J., Laclau, E. y Zizek, S. (2011), Contingencia, hegemonía, universalidad. Buenos Aires: FCE.

Cervelló, V. (2017), "La huelga de hambre penitenciaria: fundamento y límites de la alimentación forzosa", recuperado de: http://www.cienciaspenales.net/ files/2016/11/3_LA-HUELGA-DE-HAMBRE.pdf, septiembre 2017.

Derrida, J. (1992), Fuerza de ley: El "fundamento místico de la autoridad". En http:// rua.ua.es/dspace/bitstream/10045/10749/1/doxa11_06.pdf.

Fraser, N. y Honneth, A. (2006), ¿Redistribución o reconocimiento? Un debate político-filosófico. Madrid: Morata.

Informe Ethos (2011), Huelga de hambre. Santiago de Chile: Centro de Ética U. Alberto Hurtado. ISSN 0717-6430, Nro. 81.

Laclau, E. (2009), La razón populista. Buenos Aires: FCE.

Miranda-Montecinos A, García-Huidobro Correa J, Contreras-Aguirre. "La huelga de hambre como suicidio intencional. Una propuesta de valoración moral desde la tradición central de la ética". Pers.bioét. 2015; 19(1): 64-79. DOI: 10.5294/ pebi.2015.19.1.6

Montealegre, J. (2014), "Salvador Allende. Caricatura y monumento". MERIDIONAL Revista Chilena de Estudios Latinoamericanos 2, abril 2014, 39-62.

Palacios, A. “1984, más acá de la Utopía” Teaser Documental, recuperado en: https:// www.youtube.com/watch? $\mathrm{v}=\mathrm{XK} 8 \mathrm{wJgLN} 2 \mathrm{sw} \& \mathrm{t}=47 \mathrm{~s}$

Precht, J. y Faundes, J. (2013), "Legitimidad de la huelga de hambre. Un debate sobre el derecho a la vida y la dignidad humana". Estudios Constitucionales, Año 11, Nro. 2, 2013, pp. 333-368.

Ruiz M., A. (1993), “Autonomía individual y derecho a la propia vida (un análisis filosófico-jurídico)”. Revista del Centro de Estudios Constitucionales, Núm. 14. Enero-abril 1993.

Soto Kloss, Eduardo (1985), “Comentario a Sentencia CA Stgo. (9 de agosto, 1984) acción de protección acogida en derecho a la vida y a la integridad física y psíquica de las personas; caso párroco de San Roque", Revista de Derecho (Año $\left.12, \mathrm{~N}^{\circ} 1\right)$, pp. 150-162.

Spivak, G. (1998), “PPuede hablar el sujeto subalterno?”, en Nelson, C. y Grossberg, L. (comps.), Marxism and the Interpretation of Culture. Basingstoke: Macmillan Education, pp. 271-313.

Taylor, C. (1997), Argumentos filosóficos. Barcelona: Paidós.

Tugendhat, E. (2002), "Sobre la muerte” (1996), Problemas. Barcelona: Gedisa.

Villalobos R., Sergio, 1930-. "La huelga de hambre también era terrorismo" (entrevista) [artículo] Emmanuel Ganora. Las Últimas Noticias (Diario: Santiago, Chile). Archivo de Referencias Críticas.

Zizek, S. (2007), El espinoso sujeto. Buenos Aires: Paidós.

(2005), La suspensión politica de la ética. Buenos Aires: FCE.

Zizek, S. (2009) Sobre la violencia. Seis reflexiones marginales. Barcelona: Paidós. 